\title{
Molecular Motion in Poly(amino acid). III. Proton Broad Line NMR of Amorphous Silk Fibroin
}

\author{
Masanobu Nagura and Hiroshi IshIKawa \\ Faculty of Textile Science and Technology, \\ Shinshu University, Ueda 386, Japan.
}

(Received February 18, 1978)

\begin{abstract}
KEY WORDS Molecular Motion / Poly(amino acid) / Proton Broad
Line NMR / Amorphous / Silk Fibroin / Hydrogen Bond /
\end{abstract}

In preceding papers, ${ }^{1,2}$ it was clarified that the force of intermolecular hydrogen bonding in the $\beta$-form crystal of silk fiber decreased by heating above $140^{\circ} \mathrm{C}$ and that the distances between the pleated sheets then increased with molecular motion, while the silk fibroin molecules oriented parallel to the fiber axis in the amorphous part of the silk fiber.

In this paper, the molecular motion of the unoriented amorphous silk fibroin was investigated by the proton broad line NMR (B. L. NMR). B. L. NMR spectra were taken with a Varian WL-210 $\mathrm{RF}$ unit at a frequency of $30 \mathrm{MHz}$ over the temperature range from $-150^{\circ} \mathrm{C}$ to $200^{\circ} \mathrm{C}$. Preparation of the amorphous silk fibroin film of Bombyx mori has been described elsewhere. ${ }^{1}$ For measurements, the film prepared was packed randomly into a glass tube, dried in a vacuum of $10^{-5} \mathrm{mmHg}$ for $2 \mathrm{~h}$, and then sealed.

Figure 1 shows the first derivatives of B. L. NMR absorptions $\left(S^{\prime}(x)_{\text {obs }}\right)$ at various temperatures. In the figure, the intensities of spectra from $150^{\circ} \mathrm{C}$ to $90^{\circ} \mathrm{C}$ are two times those from $100^{\circ} \mathrm{C}$ to $200^{\circ} \mathrm{C}$. Each curve shows one component from $-150^{\circ} \mathrm{C}$ to $-50^{\circ} \mathrm{C}$. Above $-30^{\circ} \mathrm{C}$, the derivatives, however, were composed of two components. These derivatives decomposed, assuming that a narrow and a broad component were the first derivatives of Lorentz curve (eq 1) and of Gauss curve (eq 2), respectively. ${ }^{3}$

$$
\begin{gathered}
F^{\prime}(x)=A \cdot x /\left(B^{2}+x^{2}\right) \\
G^{\prime}(x)=C \cdot x \cdot \exp \left(-x^{2} / 2 D^{2}\right)
\end{gathered}
$$

where $A, B, C$, and $D$ are parameters. The para- meters were selected to satisfy eq 3 by computer (HITAC 8700/8800, TODAI CENTRE).

$$
\left|\left\{S^{\prime}(x)_{\text {obs }}-S^{\prime}(x)_{\mathrm{calc}}\right\} / S^{\prime}(x)_{\mathrm{obs}}\right|<0.1
$$

where $S^{\prime}(x)_{\text {calc }}=F^{\prime}(x)+G^{\prime}(x)$. In Figure 1 the dashed lines show the calculated curves of $F^{\prime}(x)$ and $G^{\prime}(x)$. $S^{\prime}(x)_{\text {calc }}$, however, was not shown in Figure 1 , because $S^{\prime}(x)_{\text {calc }}$ and $S^{\prime}(x)_{\text {obs }}$ almost overlapped with each other.

Figure 2 shows the plots of the maximum slope width $\left(\delta H_{\mathrm{m} . \mathrm{sl}}\right) v s$. temperature for the narrow and the broad components. The $\delta H_{\mathrm{m} . \mathrm{s} 1}$ of the broad component was determined from the calculated curve $\left(G^{\prime}(x)\right)$ above $100^{\circ} \mathrm{C}$, where $\delta H_{\mathrm{m} . \mathrm{sl}}=2 D$ from eq 2.

The broad component narrows in two transition steps. In preceding studies, ${ }^{4,5}$ it was proved that the narrowing of the broad component was due to rotations of the relatively long length of side chains in poly(amino acid)s, such as poly $(\gamma$-methyl L-glutamate), poly( $\gamma$-benzyl L-glutamate), poly( $\beta$-methyl L-aspartate) and poly(L-methionine) from about $-40^{\circ} \mathrm{C}$ to room temperature, while narrowing due to the rotation of the short length of side chain such as alanine residue occurs even below liquid $\mathrm{N}_{2}$ temperature. ${ }^{6}$ Glycine, alanine, serine and tyrosine are the components of amino acid in the silk fibroin. ${ }^{7} \quad$ From these facts, the narrowing at lower temperatures $\left(-20 \sim 20^{\circ} \mathrm{C}\right)$ is due to the rotation of the relatively long length of side chains, i.e., serine and tyrosine residues. On the other hand, the glass transition temperature measured by dilatometry was $175^{\circ} \mathrm{C}$, and the dispersion showing the $\tan \delta$ maximum at $175^{\circ} \mathrm{C}$ 

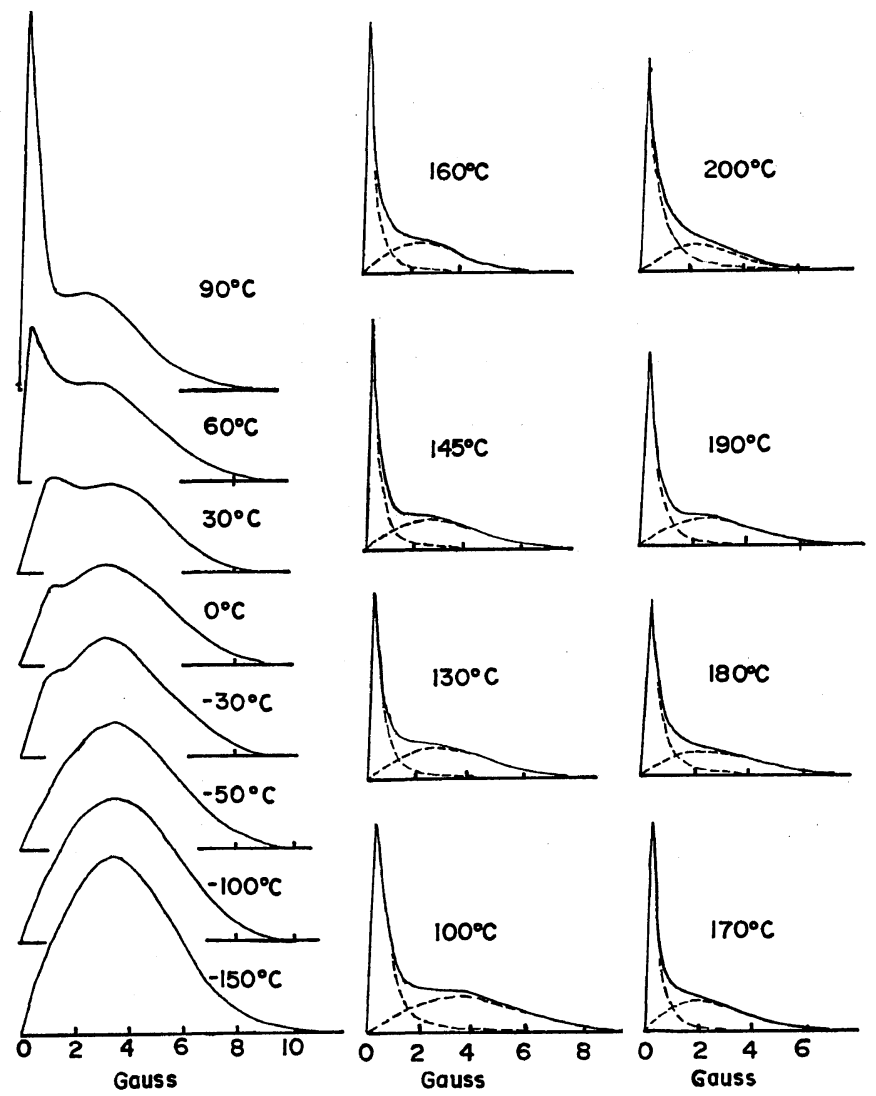

Figure 1. Halves of the first derivative of B.L.NMR spectra for the amorphous silk fibroin sample.

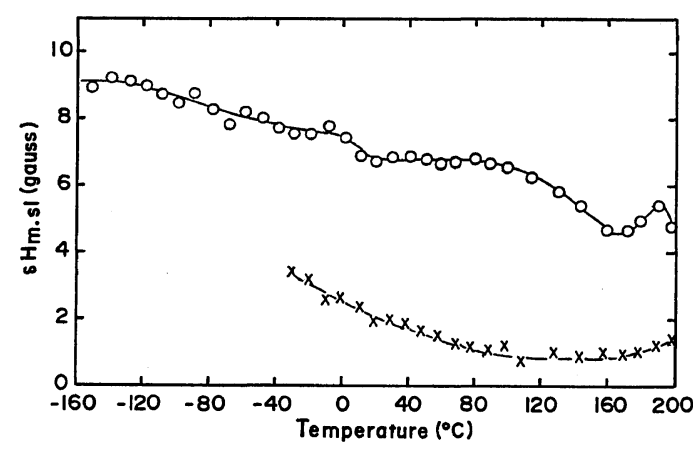

Figure 2. Plots of line width vs. temperature for the amorphous silk fibroin sample: $\bigcirc$, broad component; $\times$, narrow component.

occurred gradually above $100^{\circ} \mathrm{C}$ in the temperature dependence of viscoelasticity. ${ }^{8}$ Thus, the narrowing at higher temperatures is due to the vibration of the main chain and the successive segmental motion of the main chain. According to Ma- goshi, ${ }^{9}$ the amorphous silk fibroin molecules crystallize into $\beta$-form crystal above $180^{\circ} \mathrm{C}$. Thus, the increase in $\delta H_{\mathrm{m} . \mathrm{s} 1}$ from $180^{\circ} \mathrm{C}$ to $200^{\circ} \mathrm{C}$ means the crystallization.

Hence the rotation of side chains caused a narrowing of the broad component rather than the apparance of a narrow component; and as mentioned above, the narrow component observed here is not due to the side chains. If the water was adsorped in the sample, a sharp narrow component should be $40 \mathrm{~mm}$ gauss at above $0^{\circ} \mathrm{C}$, with a width independent of the measured temperature. ${ }^{10}$ Conversely, the width of the narrow component was as much as 4 gauss at $-30^{\circ} \mathrm{C}$ for the sample used, and narrows gradually to 1 gauss with increasing temperature. Thus, this narrow component is not due to the adsorped water. In a physical investigation, polyurethane, ${ }^{11}$ polyamide $^{12}$ and some synthetic poly(amino acid)s ${ }^{13,14}$ showed a new dispersion $\left(\beta_{2}\right)$ due to the 


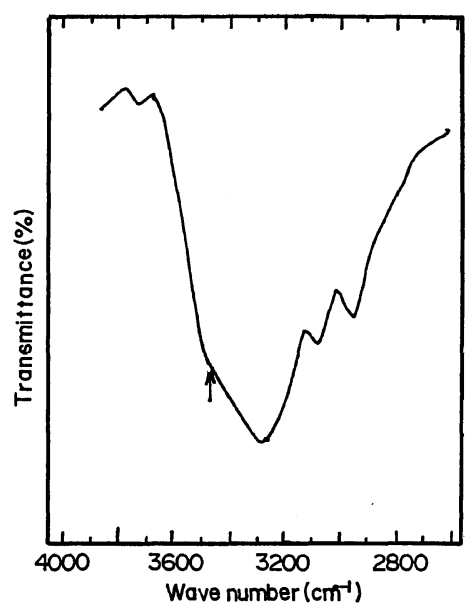

Figure 3. Infrared spectrum for the amorphous silk fibroin sample.

existence of tightly bound water. E. Baer, et al., ${ }^{13,14}$ concluded that the tightly bound water was not easily removed by vacuum drying and forms bridges between pairs of amide and peptide groups, namely forms polymer-water complex, and that the tightly bound water has no properties of normal water. There is no normal water in the used sample as described above, but the tightly bound water will be contained, since its thus removal is very difficult. It is possible to consider that the narrow component is attributable to the motion of the polymer-water complex. Furthermore, there is a considerable number of $\mathrm{NH}$ groups free from intermolecular or intramolecular hydrogen bonds formed in the process of the sample preparation, whose infrared absorption band appeared at $3480 \mathrm{~cm}^{-1}$ (Figure 3). This means that several sequential residues free from hydrogen bond exist in the silk fibroin molecules. Thus, it is also reasonable to consider that the narrowing is due to the motion of these sequential residues.

Acknowledgment. The authors wish to thank Dr. I. Kuriyama and Dr. N. Hayakawa of Japan Atomic Energy Research Institute for their variable comments and advice in these experiments.

\section{REFERENCES}

1. M. Nagura, K. Goto, and H. Ishikawa, Kobunshi Ronbunshu, 34, 389 (1977).

2. M. Nagura, M. Urushidani, H. Shinohara, and H. Ishikawa, Kobunshi Ronbunshu, 35, 81 (1978).

3. Kyoritsu, "Magnetic Resonance of Polymers," 1975, p 63.

4. K. Hikichi, J. Phys. Soc. Jpn., 19, 2169 (1964).

5. A. Tsutsumi, Japan. J. Appl. Phys., 9, 2225 (1970).

6. K. M. Sinott, J. Polym. Sci., 42, 3 (1960).

7. R. E. Marsh, R. B. Corey, and L. Pauling, Biochem. Biophys. Acta, 16, 1 (1955).

8. J. Magoshi and Y. Magoshi, J. Polym. Sci., 13, 1347 (1975).

9. J. Magoshi, Kobunshi Ronbunshu, 31, 463 (1974).

10. S. Fujiwara, J. Polym. Sci., 44, 93 (1960).

11. H. Jacobs and E. Jenckel, Makromol. Chem., 47, 72 (1961).

12. A. E. Woodward, J. M. Crissmann, and J. A. Sauter, J. Polym. Sci., 44, 23 (1960).

13. H. Shiraishi, A. Hiltner, and E. Baer, Biopolymers, 15, 1155 (1976).

14. H. Shiraishi, A. Hiltner, and E. Baer, Biopolymers, 16, 2801 (1977). 